\title{
Neurodevelopmental outcomes after biventricular repair of congenital heart defects
}

\author{
Joseph M. Forbess, $M D^{a, c}$ \\ Karen J. Visconti, $\mathrm{PhD}^{\mathrm{a}}$ \\ David C. Bellinger, PhD, MSc ${ }^{b}$ \\ Robert J. Howe, CCPa \\ Richard A. Jonas, MD ${ }^{a, c}$
}

From the Departments of Cardiovascular Surgery $^{\mathrm{a}}$ and Neuroepidemiology, ${ }^{\mathrm{b}}$ Children's Hospital, and the Department of Surgery, ${ }^{\mathrm{c}}$ Harvard Medical School, Boston, Mass.

Read at the Twenty-seventh Annual Meeting of The Western Thoracic Surgical Association, San Diego, Calif, June 20-23, 2001

Received for publication June 28, 2001; revisions requested July 27, 2001; revisions received Aug 2, 2001; accepted for publication Aug 7, 2001.

Address for reprints: Joseph M. Forbess, MD, Department of Cardiovascular Surgery, Children's Hospital, 300 Longwood Ave, Boston, MA 02115 (E-mail: forbess@ cardio.tch.harvard.edu).

J Thorac Cardiovasc Surg 2002;123:631-9

Copyright ( $(2) 2002$ by The American Association for Thoracic Surgery

$0022-5223 / 2002 \$ 35.00+0 \quad \mathbf{1 2 / 6 / 1 1 9 3 4 2}$

doi: $10.1067 / \mathrm{mtc} .2002 .119342$
Objective: This study was undertaken to assess neurodevelopment of children after biventricular repair of congenital heart defects.

Methods: Full-scale, performance, and verbal IQs of 69 patients who had undergone biventricular repair were assessed at 5 years of age with the Wechsler Preschool and Primary Scales of Intelligence-Revised. The Wide Range Assessment of VisualMotor Abilities was used to measure visual-motor skills. Regression analyses adjusting for parental IQ and socioeconomic status were used to evaluate outcome predictors.

Results: Median age at repair was 91 days (range 1-1558 days). Hypothermic circulatory arrest was used in 35 cases (mean duration of hypothermic circulatory arrest $33 \pm 17$ minutes). Mean full-scale, performance, and verbal IQs for the entire study population were within the reference range (full-scale $96.9 \pm 15.9$, performance $96.6 \pm 16.8$, verbal $97.7 \pm 15.2)$. Anatomic diagnosis, age at operation, and use of hypothermic circulatory arrest did not influence full-scale IQ $(P=.66, P=$ .14 , and $P=.46$, respectively), performance IQ $(P=.64, P=.36$, and $P=.73$, respectively), or verbal IQ $(P=.74, P=.08$, and $P=.39$, respectively). Among patients subjected to hypothermic circulatory arrest, duration of arrest was evaluated as a predictor of outcome. After adjustment for parental IQ, full-scale $(P=.12)$, performance $(P=.07)$, and verbal $(P=.22)$ IQ scores of patients with more than 39 minutes of hypothermic circulatory arrest were not different from those of patients who had arrest periods of 39 minutes or less. After adjustment for socioeconomic status, however, full-scale $(P=.05)$ and performance $(P=.03)$ IQ scores were lower among patients who had more than 39 minutes of hypothermic circulatory arrest. After adjustment for either parental IQ or socioeconomic status, patients with more than 39 minutes of arrest had lower scores on Wide Range Assessment of Visual-Motor Abilities subtests of visual-motor and fine motor abilities and on several performance IQ subtests.

Conclusions: IQs of patients who had undergone biventricular repair of congenital heart defects were within the reference range. However, hypothermic circulatory arrest for longer than 39 minutes was associated with deficits in visual-motor and fine motor skills and possibly in full-scale IQ.

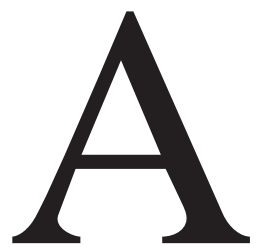

$\mathrm{s}$ the survival for patients undergoing primary biventricular repairs of critical congenital heart defects has improved, increased attention is now being paid to quality of life for these patients. An important component of quality of life is intellectual development, and defining this intellectual development has become an area of intense research. Research has largely concentrated on the evaluation of operative variables on neurodevelopment. ${ }^{1-11}$ An ongoing prospective 
randomized study of the use of hypothermic circulatory arrest (HCA) versus low-flow bypass in patients undergoing the arterial switch operation for D-transposition of the great arteries was begun at this institution in the late 1980s. Data have been obtained from these patients at 1, 2.5, 4, and 8 years of age. , $^{12-14}$ At 8 years of age, full-scale IQ (FSIQ) scores of these patients were well within the reference range and FSIQ scores were not different between treatment groups. ${ }^{14}$ The comprehensive neuropsychologic evaluation performed in that study did, however, reveal that patients subjected predominantly to HCA at the time of the arterial switch operation were at greater risk for motor function delay. ${ }^{13,14}$ Indeed, both treatment groups were noted to perform below average in some tests of visual-spatial and visual-motor skills. ${ }^{12,14}$ It now appears fairly well established that, although their FSIQs may fall within the reference range, these children appear to exhibit measurable deficits in some categories of neuropsychologic testing.

The enrollment in the Boston Circulatory Arrest Trial was limited to patients undergoing the arterial switch for D-transposition of the great arteries. ${ }^{8}$ This limitation to a single operation and diagnosis was necessary to limit both genetic and perioperative variables in that prospective randomized trial. To expand our understanding of the neurodevelopment of all of our patients, we decided to perform neuropsychologic testing at 5 years of age on all children undergoing cardiac surgery at our institution. This registry includes the entire range of anatomic diagnoses and contemporary surgical treatment strategies for these defects. It is our hope that a registry such as this may produce important normative data regarding the neurodevelopment of patients after repair of congenital heart disease. Moreover, populations that are at particularly high risk for neurodevelopmental delay may thus be identified. Finally, retrospective analyses of anatomic and operative variables can produce preliminary data that may guide the design of future prospective clinical trials.

The results for our patients with single-ventricle anatomy from this registry have been reported elsewhere. ${ }^{15}$ This study reports the data obtained from patients without transposition who underwent primary biventricular repairs at our institution.

\section{Methods}

\section{Patients}

As part of a long-term project to develop a registry-type database on the neurodevelopment of children with various congenital cardiac lesions, children who have undergone cardiac surgery at our institution are invited to return for neuropsychologic evaluation at 5 years of age. In this study patients were recruited for inclusion if they had undergone a biventricular repair for congenital heart disease at this institution, were 5 years of age, and were residents of New England or eastern New York. Parking and meal expenses were fully reimbursed. Ground transportation to Children's Hos- pital was partially subsidized. Because the developmental outcomes of patients undergoing the arterial switch operation for D-transposition of the great arteries at our institution have been comprehensively analyzed, ${ }^{7,8,12-14}$ we excluded those patients from this study. Patients with the diagnosis of velocardiofacial syndrome, as confirmed by chromosomal analysis, were excluded. Patients with Williams or Down syndrome were also excluded. From 1998, when this project began, until this writing we identified 222 patients who met these criteria. Of these eligible patients, $69(31 \%)$ participated. Fifty-nine families refused (27\%). Ninetyfour families (42\%) either were unavailable for follow-up or failed to respond. The 69 study participants underwent repair between March 1993 and August 1998. All repairs involved the use of cardiopulmonary bypass with varying degrees of hypothermia. Thirty-five patients were subjected to profound HCA. A significant portion of the perfusion records for this era have been lost, which prevented the identification of the $\mathrm{pH}$ strategy used and cooling durations for a large segment of the study population. Duration of cardiopulmonary bypass, use and duration of HCA, minimum hematocrit during cardiopulmonary bypass, and lowest rectal temperature attained were abstracted from clinical notes.

This study was approved by the Children's Hospital Committee on Clinical Investigation and was conducted in accordance with institutional guidelines. Informed consent was obtained from the parents of all participating patients.

\section{Medical Record Review}

Information was obtained from each patient's medical records concerning anatomic diagnosis, age at repair, duration of cardiopulmonary bypass, use and duration of HCA, minimum hematocrit during cardiopulmonary bypass, lowest rectal temperature attained, and length of postrepair hospital stay.

\section{Developmental Assessment}

All patients were administered the Wechsler Preschool and Primary Scale of Intelligence-Revised (WPPSI-R) ${ }^{16}$ and the Wide Range Assessment of Visual-Motor Abilities (WRAVMA). ${ }^{17}$ The WPPSI-R is a standardized measure used to assess intelligence in children aged 3 years through 7 years, 3 months. It is composed of five verbal subtests (Information, Comprehension, Arithmetic, Vocabulary, Similarities) and five performance subtests (Object Assembly, Geometric Design, Block Design, Mazes, Picture Completion), which yield separate verbal IQ (VIQ) and performance IQ (PIQ) scores. A full-scale score (FSIQ) is derived from combined performance on the VIQ and PIQ scales. Mean IQ score ( \pm SD) is $100 \pm 15$

The WRAVMA is a standardized measure used to assess visual-motor abilities in children aged 3 years through 17 years. It is composed of three subtests (Drawing, Matching, and Pegboard). These subtests assess visual-spatial (Matching), fine motor (Pegboard), and integrated visual-motor abilities (Drawing). A score for each subtest can be calculated. Mean subtest scores $( \pm S D)$ are $100 \pm 15$. A composite score is derived from the performance on the visual-motor, visual-spatial, and fine motor areas evaluated. Mean composite score $( \pm$ SD) is $100 \pm 15$.

At the time the child was being evaluated, parents were asked to complete a questionnaire on family demographic information, including parental marital status and maternal and paternal occu- 
TABLE 1. Anatomic diagnoses of study population $(n=69)$

\begin{tabular}{lrr}
\hline Diagnostic group & No. & $\%$ \\
\hline Atrial septal defect/partial anomalous & 6 & 8.7 \\
$\quad$ pulmonary venous return & & \\
Atrioventricular canal & 1 & 1.4 \\
Double-outlet right ventricle & 4 & 5.8 \\
Interrupted aortic arch & 1 & 1.4 \\
Pulmonary artery sling & 1 & 1.4 \\
Total anomalous pulmonary venous return & 3 & 4.3 \\
Tetralogy of Fallot & 20 & 28.9 \\
Truncus arteriosus & 6 & 8.7 \\
Ventricular septal defect & 19 & 27.5 \\
Other* & 8 & 11.6 \\
\hline
\end{tabular}

*0ther defects included anomalous origin of left coronary artery from pulmonary artery, cortriatriatum, and subaortic membrane.

pational and educational information. Parental IQ was assessed with the Kaufman Brief Intelligence Test. ${ }^{18}$ Socioeconomic status was determined with the Hollingshead Four Factor Index of Social Status. ${ }^{19}$ This index calculates socioeconomic status on the basis of parental occupation and educational levels. Parental occupations are stratified into 9 categories (eg, 1 for a laborer, 6 for a technician, and 9 for a professional). Education is scored on a scale of 1 to 7 (eg, 1 for a 7th-grade education and 7 for a graduate degree). Parental IQ and socioeconomic status are typically predictors of child IQ. ${ }^{20} \mathrm{We}$ therefore adjusted for parental IQ or socioeconomic status in some of our statistical analyses. All evaluations were conducted by the same psychologist (K.J.V).

\section{Statistical Analysis}

The association between continuous predictor and outcome variables was estimated with univariate regression analysis, with adjustment for parental IQ or socioeconomic status. Descriptive statistics were used to present the medical and sociodemographic data of the sample.

\section{Results}

\section{Patient Characteristics}

Preoperative anatomic diagnoses among the study group are summarized in Table 1. The median age at repair was 91 days (range 1-1558 days). The median interval between surgery and testing was 1806 days (range 423-2025 days). HCA was used in 35 cases. Median HCA time was 39 minutes (range 2-59 minutes). Patients who underwent HCA were younger at the time of repair than patients who did not undergo HCA (mean 2 months vs 13 months, $P=$ .0007). A summary of additional operative variables is presented in Table 2 .

In general, the families of patients who had undergone biventricular repair were intact, white, and middle class (Table 3). There were 36 male (52\%) and 33 female (48\%) patients. Twelve children (17.4\%) were currently receiving speech and language therapy. Eleven children (15.9\%) were receiving occupational therapy. Six children $(8.7 \%)$ were receiving physical therapy.
TABLE 2. Medical variables

\begin{tabular}{lrrc}
\hline Variable & Mean & SD & Range \\
\hline Age at repair (d) & 234.3 & 369.6 & $1-1558$ \\
Total duration of HCA (min)* & 33.4 & 16.7 & $2-59$ \\
Total duration of & 104.2 & 44.1 & $37-250$ \\
$\quad$ cardiopulmonary bypass (min)† & & & \\
Temperature (coldest, $\left.{ }^{\circ} \mathrm{C}\right)$ & 20.3 & 5.7 & $13-35$ \\
Hematocrit (\%, minimum) & 21.9 & 2.4 & $17-27$ \\
Time from repair to discharge (d) & 10.2 & 10.4 & $1-69$ \\
\hline
\end{tabular}

TABLE 3. Sociodemographic variables

\begin{tabular}{lc}
\hline Variable & \\
\hline Parents' marital status (\%) & \\
$\quad$ Married & $63 \%$ \\
Father & \\
$\quad$ Occupation status* (mean \pm SD) & $6.5 \pm 2.1$ \\
$\quad$ Education (y, mean \pm SD) & $15.1 \pm 2.6$ \\
Mother & $69 \%$ \\
$\quad$ Employed (\%) & $4.5 \pm 3.4$ \\
$\quad$ Occupation status* (mean \pm SD) & $15.5 \pm 2.6$ \\
$\quad$ Education (y, mean \pm SD) & \\
Ethnicity & $66 \%$ \\
$\quad$ White (\%) & \\
Birth order & $48 \%$ \\
$\quad$ First born (\%) & \\
Social class & \\
$\quad$ Hollingshead Four Factor Index of Social Class & \\
$\quad$ (mean \pm SD) & $50.4 \pm 10.2$ \\
Parental I0 (mean \pm SD) & \\
$\quad$ Composite & $106.1 \pm 8.2$ \\
$\quad$ Vocabulary & $105.4 \pm 9.6$ \\
$\quad$ Matrices & $105.6 \pm 7.4$
\end{tabular}

*0ccupations were ranked on a scale of 1 (laborer) to 9 (professional). tScores on the Hollingshead Four Factor Index of Social Class, with higher score indicating higher social class. ${ }^{19}$

$\ddagger$ Score on the Kaufman Brief Intelligence Test. ${ }^{18}$

\section{Developmental Assessment}

General intelligence. Mean IQ scores were within $1 \mathrm{SD}$ $( \pm 15)$ of the normative population mean of 100 . In the group as a whole, mean FSIQ was $96.9 \pm 15.9$ (range 61-133). Four children (6\%) had FSIQ scores below 70 . Mean VIQ was $97.7 \pm 15.2$ (range 55-135), and mean PIQ was $96.6 \pm 16.7$ (range 61-145).

Visual-motor and visual-spatial skills. The group also performed within the average range in terms of visual-motor skills. Mean composite score on the WRAVMA was $97.1 \pm$ 17.2 (range 45-130). With respect to the individual subtests, mean score on Drawing was $97.6 \pm 15.3$ (range 59-129). Mean score on Matching was $102.9 \pm 12.6$ (range 57-134), and mean score on Pegboard was $95.0 \pm 16.3$ (range 45-141). 


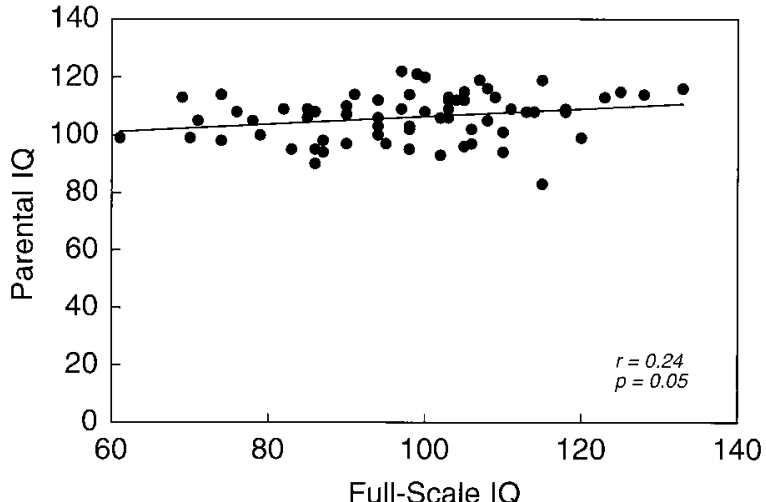

Figure 1. FSIO scores of study population as function of parental I0 ( $r=0.24, P=.05)$.

\section{Risk Factor Analysis}

Figure 1 displays the FSIQ scores of the study population as a function of parental IQ. Figure 2 shows FSIQ scores as a function of socioeconomic status. Because of the positive correlations between FSIQ and parental IQ $(r=0.24, P=$ $.05)$ and FSIQ and socioeconomic status $(r=0.39, P=$ $.001)$, separate univariate regressions adjusted for parental IQ or socioeconomic status were carried out to determine whether other anatomic, surgical, or intraoperative variables were associated with intelligence scores or visual-motor skills. Table 4 displays the variables examined as possible risk factors for worse developmental outcome. Anatomic diagnosis, age at operation, duration of cardiopulmonary bypass, lowest hematocrit, lowest temperature, use of HCA, duration of HCA, and postoperative hospital stay did not predict FSIQ, PIQ, or VIQ when adjusted for either parental IQ or socioeconomic status.

Among the 35 patients subjected to HCA, duration of HCA was evaluated as a predictor of outcome. The median duration of HCA was used as a cutoff point to examine differences between patients who underwent 39 minutes of HCA or less $(n=19)$ and those who underwent more than 39 minutes of HCA $(n=16)$ with respect to outcome variables. After adjustment for parental IQ, patients subjected to HCA for longer than 39 minutes did not differ significantly from patients who underwent HCA for 39 minutes or less on FSIQ $(P=.12)$, VIQ $(P=.22)$, or PIQ $(P=.07)$ scores (Table 5). Use of HCA for longer than 39 minutes was associated with lower scores on several performance, or nonverbal, subtests, including Geometric Design $(P=.02)$, Block Design $(P=.05)$, Picture Completion $(P=.02)$, and Animal Pegs $(P=.004)$. Group differences were also found in WRAVMA composite score $(P=.05)$ and Pegboard $(P=.02)$ subtest scores (Table 5). Differences on the Drawing subtest approached significance $(P=$ $.07)$.

After adjustment for socioeconomic status, patients sub-

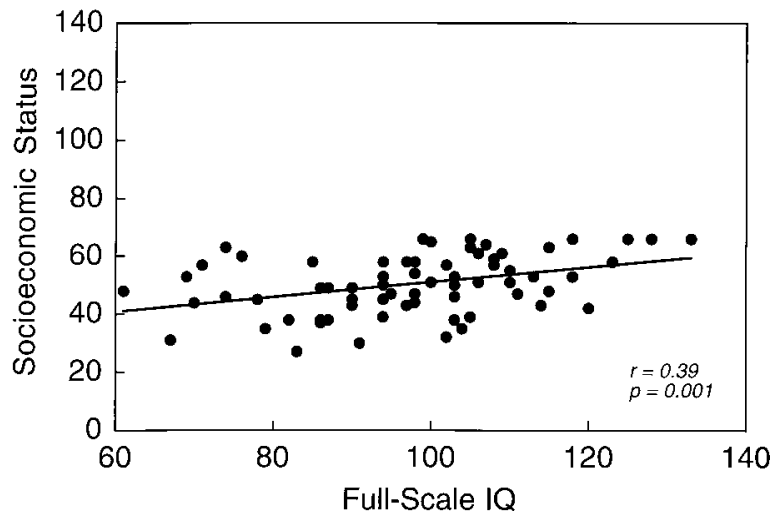

Figure 2. FSIO scores of study population as function of socioeconomic status $(r=0.39, P=.001)$.

jected to HCA for longer than 39 minutes scored significantly lower than did patients who underwent HCA for 39 minutes or less on FSIQ $(P=.05)$ and PIQ $(P=.03$, Table 5). Once again, use of HCA for longer than 39 minutes was associated with lower scores on several performance, or nonverbal, subtests, including Geometric Design $(P=.02)$, Block Design $(P=.02)$, Picture Completion $(P=.01)$, and Animal Pegs $(P=.0001)$. Group differences were also found on the WRAVMA composite score $(P=.04)$ and scores of the Drawing $(P=.05)$ and Pegboard $(P=.01)$ subtests (Table 5).

\section{Discussion}

On the whole, these children had IQs largely within the reference range after the biventricular repair of congenital heart defects. The data from this heterogeneous population were similar to those obtained from the more homogeneous population studied in the Boston Circulatory Arrest Trial. ${ }^{14}$ Parental IQ and socioeconomic status were predictors of PIQ, VIQ, and FSIQ in this study group. After adjustment for parental IQ or socioeconomic status, no patient- or procedure-specific variable predicted neurodevelopmental outcome in univariate analysis. Of those variables examined, none has drawn the critical attention of investigators more than HCA. In this study the use of HCA did not emerge as a risk factor for lower IQ (Table 4). This finding is similar to the data obtained from patients at 8 years of age in the Boston Circulatory Arrest Trial. ${ }^{14}$ Although the presence or absence of HCA did not predict IQ, duration of HCA within the HCA group may be important. After adjustment for parental IQ, there was a trend toward lower FSIQ with HCA for longer than 39 minutes (Table 5). After adjustment for socioeconomic status, however, FSIQ was significantly lower among patients who were subjected to more than 39 minutes of HCA (Table 5). Future analyses with larger sample sizes will be required to strengthen this conclusion. 
TABLE 4. Risk factors for lower I0 scores

\begin{tabular}{|c|c|c|c|c|c|c|}
\hline \multirow[b]{2}{*}{ Variable } & \multicolumn{2}{|c|}{ Full-scale I0 } & \multicolumn{2}{|c|}{ Performance I0 } & \multicolumn{2}{|c|}{ Verbal I0 } \\
\hline & $\begin{array}{l}P \text { value } \\
\text { adjusting for } \\
\text { parental } 10^{*}\end{array}$ & $\begin{array}{c}P \text { value adjusting } \\
\text { for socioeconomic } \\
\text { statust }\end{array}$ & $\begin{array}{c}P \text { value } \\
\text { adjusting for } \\
\text { parental } 10^{*}\end{array}$ & $\begin{array}{c}P \text { value adjusting } \\
\text { for socioeconomic } \\
\text { status }\end{array}$ & $\begin{array}{c}P \text { value } \\
\text { adjusting for } \\
\text { parental } 10^{*}\end{array}$ & $\begin{array}{c}P \text { value adjusting } \\
\text { for socioeconomic } \\
\text { status }\end{array}$ \\
\hline Anatomic diagnosis & .66 & .54 & .64 & .37 & .74 & .83 \\
\hline Age at operation & .14 & .16 & .36 & .44 & .08 & .07 \\
\hline Use of HCA & .46 & .33 & .73 & .51 & .39 & .36 \\
\hline Total duration of HCA & .16 & .1 & .19 & .11 & .2 & .15 \\
\hline $\begin{array}{l}\text { Total duration of cardiopulmonary } \\
\text { bypass }\end{array}$ & .74 & .92 & .63 & .91 & .82 & .86 \\
\hline Temperature (coldest) & .81 & .87 & .66 & .79 & .98 & .96 \\
\hline Hematocrit (\%, minimum) & .9 & .97 & .74 & .8 & .92 & .89 \\
\hline Time from repair to discharge & .47 & .37 & .33 & .31 & .71 & .54 \\
\hline
\end{tabular}

${ }^{*} P$ value from regression model adjusting for parental 10 as determined by the Kaufman Brief Intelligence Test. ${ }^{18}$

$\dagger P$ value from regression model adjusting for family socioeconomic class according to the Hollingshead Four Factor Index of Social Class. ${ }^{19}$

TABLE 5. Developmental outcomes of patients with HCA

\begin{tabular}{|c|c|c|c|c|c|c|}
\hline & \multicolumn{2}{|c|}{$\begin{array}{c}\leq 39 \min \mathrm{HCA} \\
(\mathrm{n}=19)\end{array}$} & \multicolumn{2}{|c|}{$\begin{array}{c}>39 \text { min HCA } \\
\left(n=14^{*}\right)\end{array}$} & \multirow{2}{*}{$\begin{array}{c}P \text { value } \\
\text { adjusted for } \\
\text { parental IO† }\end{array}$} & \multirow{2}{*}{$\begin{array}{c}P \text { value } \\
\text { adjusted for } \\
\text { socioeconomic } \\
\text { status } \ddagger\end{array}$} \\
\hline & Mean & SD & Mean & SD & & \\
\hline \multicolumn{7}{|c|}{ Intelligence measures§ } \\
\hline Full-scale I0 & 104.3 & 11.6 & 94.3 & 21.9 & .12 & .05 \\
\hline Performance 10 & 104.2 & 8.6 & 92.1 & 25.5 & .07 & .03 \\
\hline Verbal IO & 103.9 & 15.2 & 96.1 & 17.4 & .22 & .16 \\
\hline \multicolumn{7}{|c|}{ Visual-motor measure $\|$} \\
\hline Composite score & 103.3 & 7.9 & 90.4 & 25.3 & .05 & .04 \\
\hline Drawing & 103.5 & 12.7 & 93.0 & 17.8 & .07 & .05 \\
\hline Matching & 103.8 & 6.6 & 105.4 & 16.4 & .68 & .74 \\
\hline Pegboard & 100.9 & 12.2 & 87.4 & 18.2 & .02 & .01 \\
\hline
\end{tabular}

*Although 16 patients underwent HCA for longer than 39 minutes, parents of 2 of these patients were not administered the Kaufman Brief Intelligence Test, ${ }^{18}$ and those patients' scores were not used in analysis.

$\dagger P$ value from regression model adjusting for parental $I 0$ as determined by the Kaufman Brief Intelligence Test. ${ }^{18}$

$\ddagger P$ value from regression model adjusting for family socioeconomic class according to the Hollingshead Four Factor Index of Social Class. ${ }^{19}$

$\S$ Wechsler Preschool and Primary Scales of Intelligence-Revised was used to measure intelligence. ${ }^{16}$

|The Wide Range Assessment of Visual Motor Abilities was used to assess visual-motor skills. ${ }^{17}$

In this study, within the group of patients subjected to HCA there were also differences between patients subjected to more than 39 minutes of HCA and those subjected to 39 minutes of HCA or less on tests of visual-motor and visualspatial skills. Those patients with more than 39 minutes of HCA clearly had lower scores on these tests of higher order nonverbal processing, such as the WRAVMA. These differences were present regardless of adjustment for parental IQ or socioeconomic status (Table 5). This spectrum of disability is similar to that detected in patients after the arterial switch procedure at this and other institutions. ${ }^{2,21,22}$ Deficiencies in these domains are also seen in other similar adult and pediatric populations considered to be at risk because of a history of cerebral anoxia with or without a history of extracorporeal mechanical circulatory support. ${ }^{23-25}$
Despite these concerns related to mechanical circulatory support, cardiopulmonary bypass time and other supportrelated variables were not predictors of worse outcomes on these neuropsychologic tests. As the number of variables examined increases in studies of such relatively small size, however, drawing conclusions from retrospective data becomes difficult, particularly when the expected differences are fairly subtle. Moreover, the retrospective evaluation of almost any support-related variable is limited in this patient population because of the lack of both internal or external control data. External control subjects who were not operated on are difficult if not impossible to obtain, because many of these defects are lethal without repair or palliation. Internal control data are likewise impossible to obtain for these patients, who generally undergo their operations at ages that preclude preoperative neuropsychologic testing. 
This is not the case in adult populations, where elegant demonstrations of cognitive decline after cardiopulmonary bypass have been possible. ${ }^{26}$

It is also important to note that assigning increased morbidity to HCA longer than 39 minutes may not be entirely sound, because the methods for this technique have changed significantly at this institution during recent years. On the basis of data from animal models and clinical trials, we changed from alpha-stat $\mathrm{pH}$ management to a $\mathrm{pH}$-stat strategy in 1996. ${ }^{2,5,27,28}$ Eleven patients in this study were previously enrolled in a prospective randomized trial addressing this issue ${ }^{2}$ and were independently evaluated for inclusion here. As mentioned previously, data on $\mathrm{pH}$ management strategy could not be obtained for most of this study population because the perfusion records for that era are missing. More recently we have been routinely using a higher hematocrit on cardiopulmonary bypass, approximately $30 \%$. The mean hematocrit in this study population was $21.9 \%$. This change in hematocrit management was also motivated by preclinical animal model data and by strongly suggestive data from clinical studies. ${ }^{29-31}$ We believe that one must recognize that although HCA clearly carries some potential for neurologic injury, this potential may have been reduced by the described modifications. We speculate that the "critical point," or the temporal threshold after which neurologic injury is extremely likely, has possibly been extended with these measures as well. The evolving nature of the specific method of HCA must be taken into consideration when examining this support technique as a potential risk factor for developmental morbidity.

In addition to parental influence and operative variables, the genotypic propensity toward developmental delay in these patients with congenital heart disease must be considered. Overt examples of this propensity would be clear if one were, for example, to evaluate the IQs of the patients representing an institution's experience with the repair of complete atrioventricular septal defect. This group would almost certainly have lower IQs than the reference range. This would not necessarily be because of any operative variable, but rather because of the prevalence of trisomy 21 in this group. A similar example is the prevalence of Williams syndrome among patients with supravalvular aortic stenosis. A more recently defined association is that of the deletions on chromosome 22 and such cardiac defects as interrupted aortic arch, truncus arteriosus, and tetralogy of Fallot. ${ }^{32}$ These $22 \mathrm{q} 11$ deletions, as seen in DiGeorge or velocardiofacial syndrome, frequently result in such conotruncal cardiac defects and a constellation of noncardiac findings, including developmental delay. ${ }^{32}$

Because one of the aims of this study was to provide an intrainstitutional comparison between patients with biventricular repair and our patients with repaired D-transposition of the great arteries, we excluded patients with these defined syndromes from this analysis. No anatomic diagnosis emerged from the present analysis as posing a risk for worse neurodevelopment. The strength of this conclusion is limited, however, by the low numbers of patients in each diagnostic group and by the exclusion of patients with syndromes known to result in developmental delay. Indeed, a comparison against only the two largest groups, ventricular septal defect $(n=19)$ and tetralogy of Fallot $(n=20)$, would require a sample of 13 patients to yield $80 \%$ power to detect a difference of 15 IQ points $(P=.05)$. In addition, routine chromosomal analysis was not performed on the study population. It is therefore possible that some patients with 22q11 deletions who did not overtly manifest the velocardiofacial syndrome were included in the study. This lack of correlation between anatomic diagnosis and neurodevelopment may not hold up in a comprehensive analysis of this entire registry, which is now underway. In that analysis of a population that now numbers more than 200 patients, we intend to relax these inclusion criteria so that genotypic influences may be more readily discerned.

A significant limitation of this study is the possibility of selection bias. As described previously, these data are a portion of a registry in development wherein we are attempting to test all patients from our geographic region who have undergone heart surgery at our institution. Because enrollment is voluntary, the population is subject to selection bias. The mean socioeconomic status score of 50.4 in the study population is, for example, significantly higher than the mean values of 42 and 43 seen in two previous prospective randomized trials performed at this institution. ${ }^{2,13}$ This raises the possibility that the IQ scores of the study population might overestimate those of the entire population undergoing biventricular repairs. These data are, however, only suggestive of possible selection bias. This bias cannot be confirmed or refuted without obtaining socioeconomic status data from those families that did not participate in the study.

In conclusion, patients with conditions other than Dtransposition of the great arteries who underwent primary biventricular repairs for congenital heart disease had FSIQs that were, on average, within the reference range. Parental IQ and socioeconomic status were both predictors of patient IQ at 5 years of age. No operative variable other than the use of HCA for longer than 39 minutes predicted lower scores in our extensive neuropsychologic testing. Patients subjected to more than 39 minutes of HCA had lower scores on tests of visual-motor and visual-spatial performance skills and may in fact have had lower FSIQ scores. Modifications in our HCA methods since the performance of these surgical repairs probably limit the application of this apparent threshold to patients in the current era. No anatomic diagnosis emerged as carrying higher risk for worse developmental outcomes. Future analyses with larger sample sizes 
may allow us to more accurately assess potential genotypic contributions to developmental delay among these patients with important congenital heart disease.

\section{References}

1. Jonas RA, Bellinger DC, Rappaport LA, Wernovsky G, Hickey PR, Farrell DM, et al. Relation of pH strategy and developmental outcome after hypothermic circulatory arrest. J Thorac Cardiovasc Surg. 1993; 106:362-8.

2. Bellinger DC, Wypij D, du Plessis AJ, Rappaport LA, Riviello J, Jonas RA, et al. Developmental and neurologic effects of alpha-stat versus $\mathrm{pH}$-stat strategies for deep hypothermic cardiopulmonary bypass in infants. J Thorac Cardiovasc Surg. 2001;121:374-83.

3. Oates RK, Simpson JM, Turnbull JA, Cartmill TB. The relationship between intelligence and duration of circulatory arrest with deep hypothermia. J Thorac Cardiovasc Surg. 1995;110:786-92.

4. Utens EM, Verhulst FC, Duivenvoorden HJ, Meijboom FJ, Erdman RA, Hess J. Prediction of behavioural and emotional problems in children and adolescents with operated congenital heart disease. Eur Heart J. 1998;19:801-7.

5. du Plessis AJ, Jonas RA, Wypij D, Hickey PR, Riviello J, Wessel DL, et al. Perioperative effects of alpha-stat versus $\mathrm{pH}$-stat strategies for deep hypothermic cardiopulmonary bypass in infants. $J$ Thorac Cardiovasc Surg. 1997;113:991-1000.

6. Fallon P, Aparicio JM, Elliott MJ, Kirkham FJ. Incidence of neurological complications of surgery for congenital heart disease. Arch Dis Child. 1995;72:418-22.

7. Bellinger DC, Wernosky G, Rappaport LA, et al. Cognitive development of children following early repair of transposition of the great arteries using deep hypothermic circulatory arrest. Pediatrics. 1991; 87:701-7.

8. Bellinger DC, Jonas RA, Rappaport LA, Wypij D, Wernovsky G, Kuban KC, et al. Developmental and neurologic status of children after heart surgery with hypothermic circulatory arrest or low-flow cardiopulmonary bypass. N Engl J Med. 1995;332:549-55.

9. Haneda K, Itoh T, Togo T, Ohmi M, Mohri H. Effects of cardiac surgery on intellectual function in infants and children. Cardiovasc Surg. 1996;4:303-7.

10. Miller G, Tesman JR, Ramer JC, Baylen BG, Myers JL. Outcome after open-heart surgery in infants and children. J Child Neurol. 1996;11: 49-53.

11. Eke CC, Gundry SR, Baum MF, Chinnock RE, Razzouk AJ, Bailey LL. Neurologic sequelae of deep hypothermic circulatory arrest in cardiac transplant infants. Ann Thorac Surg. 1996;61:783-8.

12. Bellinger DC, Rappaport LA, Wypij D, Wernovsky G, Newburger JW. Patterns of developmental dysfunction after surgery during infancy to correct transposition of the great arteries. J Dev Behav Pediatr. 1997; 18:75-83.

13. Bellinger DC, Wypij D, Kuban KC, Rappaport LA, Hickey PR, Wernovsky G, et al. Developmental and neurological status of children at 4 years of age after heart surgery with hypothermic circulatory arrest or low-flow cardiopulmonary bypass. Circulation. 1999;100: 526-32.

14. Bellinger DC, Wypij D, du Plessis AJ, Rappaport LA, Jonas RA, Wernovsky G, et al. Neurodevelopmental status at eight years in children with D-transposition of the great arteries: the Boston circulatory arrest trial. Presented at the 73rd Scientific Sessions of the American Heart Association, New Orleans, 2000.

15. Forbess JM, Visconti KJ, Bellinger DC, Jonas RA. Neurodevelopmental outcomes in children after the Fontan operation. Circulation. 2001;104:12 Suppl 1:I127-32.

16. Wechsler D. Wechsler preschool and primary scale of intelligencerevised manual. San Antonio (TX): The Psychological Corporation; 1989.

17. Adams W, Sheslow D. Wide Range assessment of visual motor abilities. Wilmington (DE): Wide Range; 1995.

18. Kaufman A, Kaufman N. Kaufman brief intelligence test. Circle Pines $(\mathrm{MN})$ : American Guidance Service; 1990.
19. Hollingshead A. Four factor index of social status. New Haven (CT): Yale University Press; 1975.

20. Bouchard T, McGue M. Familial studies of intelligence: a review. Science. 1981;212:1055-9.

21. Ellerbeck KA, Smith ML, Holden EW, McMenamin SC, Badawi MA, Brenner JI, et al. Neurodevelopmental outcomes in children surviving d-transposition of the great arteries. J Dev Behav Pediatr. 1998;19: $335-41$.

22. Hovels-Gurich HH, Seghaye MC, Dabritz S, Messmer BJ, von Bernuth G. Cognitive and motor development in preschool and schoolaged children after neonatal arterial switch operation. J Thorac Cardiovasc Surg. 1997;114:578-85.

23. Tindall S, Rothermel R, Delamater A, et al. Neuropsychological abilities of children with cardiac disease treated with extracorporeal membrane oxygenation. Dev Neuropsychol. 1999;16:101-15.

24. Caine D, Watson JD. Neuropsychological and neuropathological sequelae of cerebral anoxia: a critical review. J Int Neuropsychol Soc. 2000;6:86-99.

25. Sobota W, Evans J, Rowe R. Selective vulnerability of visual integrative functioning after cardiopulmonary arrest. Int J Clin Neuropsychol. 1988; 10:145-55.

26. Newman MF, Kirchner JL, Phillips-Bute B, Gaver V, Grocott H, Jones RH, et al. Longitudinal assessment of neurocognitive function after coronary-artery bypass surgery. N Engl J Med. 2001;344:395402.

27. Hiramatsu T, Miura T, Forbess JM, Du Plessis A, Aoki M, Nomura F, et al. $\mathrm{pH}$ strategies and cerebral energetics before and after circulatory arrest. J Thorac Cardiovasc Surg. 1995;109:948-57.

28. Aoki M, Nomura F, Stromski ME, Tsuji MK, Fackler JC, Hickey PR, et al. Effects of $\mathrm{pH}$ on brain energetics after hypothermic circulatory arrest. Ann Thorac Surg. 1993;55:1093-103.

29. Visconti KJ, Bichell DP, Jonas RA, Newburger JW, Bellinger DC. Developmental outcome after surgical versus interventional closure of secundum atrial septal defect in children. Circulation. 1999;100(19 Suppl):II145-50.

30. Shin'oka T, Shum-Tim D, Laussen PC, Zinkovsky SM, Lidov HG, du Plessis A, et al. Effects of oncotic pressure and hematocrit on outcome after hypothermic circulatory arrest. Ann Thorac Surg. 1998;65:15564.

31. Shin'oka T, Shum-Tim D, Jonas RA, Lidov HG, Laussen PC, Miura $\mathrm{T}$, et al. Higher hematocrit improves cerebral outcome after deep hypothermic circulatory arrest. J Thorac Cardiovasc Surg. 1996;112: 1610-20.

32. Emanuel BS, Budarf ML, Scambler PJ. The genetic basis of conotruncal cardiac defects: the chromosome 22q11.2 deletion. In: Harvey RP, Rosenthal N, editors. Heart development. San Diego: Academic Press; 1999. p. 463-78.

\section{Discussion}

Dr Leonard Bailey (Loma Linda, Calif). I acknowledge the clear and understandable organization of the data as described and presented by Forbess and colleagues from Boston.

A medical oncologist friend of mine born in 1955 with a large isolated ventricular septal defect failed to thrive in early infancy because of uncontrollable heart failure. He was referred by Richard Bing to the already legendary C. Walton Lillehei at the University of Minnesota. My friend was so young and so small that he was at first turned down for corrective surgery. However, at the persistence of the baby's mother, who was a nurse, Lillehei was finally persuaded to attempt repair of the ventricular septal defect. He agreed to do this only after informing my friend's mother that if her baby survived at all he would almost certainly have significant mental retardation and cerebral palsy. A prototype DeWall bubble oxygenator was used. My friend did survive and went on to obtain a $\mathrm{PhD}$ from Stanford and an MD from Harvard. He considers 
himself fortunate, and indeed he is. Neurodevelopmental outcomes were clearly as much of a concern to Lillehei and the other pioneers of heart surgery as they are to those of us involved today. Forbess and colleagues are correct in moving the focus of our attention beyond patient survival and onward to the quality of that survival. Studying neurologic injury associated with cardiac surgery, however, is a much more difficult task, as Gene Blackstone pointed out in a recent editorial in The Journal of Thoracic and Cardiovascular Surgery.

Forbess and colleagues used a battery of standardized assessments rather than high technology to evaluate neurodevelopmental outcomes among 69 patients 5 years of age who had undergone biventricular repair during infancy. HCA was used in half of the cases. As pointed out by Forbess and colleagues, the only operative variable associated with significant neurodevelopmental delay was the use of HCA for longer than 39 minutes. Despite the clear limitations of the retrospective study design, the small number of volunteer subjects, and the inability to compare adequate control subjects, these preliminary data seem to suggest that generous use of HCA as used in Boston at that time may compromise neuropsychologic outcome. I believe that this is the message.

Many of us have intuitively moved away from regular use of HCA in favor of other equally effective surgical strategies. The Loma Linda bias at present is to use the protection of hypothermia at $20^{\circ} \mathrm{C}$ coupled with aggressive hemodilution to ensure capillary perfusion. We use flow rates ranging from 20 to $40 \mathrm{~mL} \cdot \mathrm{kg}^{-1}$. $\mathrm{min}^{-1}$. If HCA is used at all, it is for brief periods. If more than one period of HCA is anticipated, we use interval perfusion between arrest periods. This same basic approach is used for nearly all complex congenital surgery that we perform. Although we believe that our patients generally have excellent central nervous system outcomes, we have not systemically studied this issue except among infant transplant recipients until quite recently. My colleague in pediatric neurology, Steve Ashwal, and others from Loma Linda University Children's Hospital will soon report preliminary findings of our own prospective randomized evaluation of the operative strategy just described. Both preoperative and serial postoperative magnetic resonance imaging and spectroscopy have been accomplished in an institutional review board-approved pilot study, and we are eager to report these findings.

I have just two questions for Dr Forbess. First, 4 of the children involved in your study had FSIQ scores lower than 70, which would suggest a serious handicap. Were these all among the 16 study patients who underwent prolonged HCA?

Dr Forbess. It was about 50:50 on that, actually. One of the patients who had the most profound delay actually had no circulatory arrest other than a cardiac arrest in the intensive care unit.

Dr Bailey. That gives rise to the second part of this question. Did these patients have perioperative events outside the variables examined, such as cardiac arrest, seizures, or profound hypoxemia? Could you perhaps shed light on these effects on their outcomes?

Dr Forbess. The patient who did end up with a fairly profound delay had an arrest with seizures outside the operating room during the acute postoperative period, but we were not really able to analyze that because we only had 1 patient with those particular problems.
Dr Bailey. For my second question, not included in your evaluation of these 69 children were some potentially significant preoperative variables that could compromise central nervous system outcomes independent of operative strategies. Do you believe that preoperative issues might seriously affect late neurologic outcome? Do you have any plans to include variables such as cardiovascular collapse, profound acidosis or hypoglycemia, hypercyanotic spells, protracted congestive heart failure, nutritional depletion, and other comorbidities in your ongoing studies?

Dr Forbess. On that last issue, we did plan to do this, but it became difficult. We were able to look at things such as lowest $\mathrm{pH}$ and whether the patient had a frank cardiac arrest before coming in, but when one starts to look at the episodes of hypercyanosis in the patients with tetralogy, you know as well as I do how it is with a neurologist-how many seizures do they actually see? Well, they see a lot of postictal patients, but they do not see that many seizures. I became uncomfortable with defining the number of patients who had actually had hypercyanosis. I can tell you that preoperative cardiovascular collapse did not seem to come out as significant. Again, I only had about 5 or 6 affected patients in this particular patient population. This is much more of an issue in patients with single-ventricle anatomy, but in a large analysis of the hypoplastic left heart syndrome experience at Boston that I performed in the early 1990s, lowest $\mathrm{pH}$ was not a predictor and prenatal diagnosis, which is sort of a surrogate marker for those issues, was not a predictor either.

Dr John Hawkins (Salt Lake City, Utah). I would like to commend you on this study. I think that this is an important area for us to understand what we are doing to these patients from a neurodevelopmental outlook. I have a couple quick questions. First, why did you choose to exclude patients with transposition of the great arteries? This is a large group and may give even more power to your study of differentiating this problem over the long term.

Dr Forbess. Inclusion of patients with transposition would have added about 20 patients to this group. We have published the transposition results from this institution, and the full-scale IQs came out similar to what we found here. I wanted to look at the comparison group of patients without transposition with biventricular repairs to see whether they were similar to the results from our prospective randomized trials. I wanted to see whether the patients with transposition that we previously described represented outliers, either high or low, from our standard population with biventricular repairs.

Dr Hawkins. My second question has to do with the conduct of HCA. I notice that your coldest temperature reached was more than $20^{\circ} \mathrm{C}$.

Dr Forbess. That was for all patients, so that includes a mixture of patients with and without HCA.

Dr Hawkins. That is where I was confused, because I was concerned about trying to go longer than 39 minutes for HCA at a temperature greater $20^{\circ} \mathrm{C}$.

Dr Forbess. We typically go for around $15^{\circ} \mathrm{C}$.

Dr David Clarke (Denver, Colo). I enjoyed your presentation, but one thing that struck me is that you started out with a group of 222 children and ended up with only $30 \%$ of them in the study. More than half could not be contacted, and approximately $15 \%$ of them refused to cooperate with the study. You must have thought 
about this; can you tell us what kind of selection bias you consider that this might have introduced into your study?

Dr Forbess. The possibility of selection bias concerns us a great deal. We have wanted to develop this database to generate what we think are normative data for this patient population, because this is something that we have not really done before. We have done prospective randomized trials, which have eliminated a lot of the noise from various diagnoses, but the question in a voluntary retrospective study is, are these parents more likely to bring us smart kids or dumb kids? We do not know. I think that only time will tell as we accrue more and more patients, but it is a difficult question, and the honest answer is that we do not know.

\section{JTCVS On-Line Manuscript Submission and Review}

Please visit http://www.editorialmanager.com/jtcvs/

Effective September 15, 2001, authors and reviewers may submit manuscripts and reviews electronically via Editorial Manager, our new Web-based system with full electronic submission, review, and status update capabilities.

As we move from paper to electronic submissions, the Editorial Office will make proxy submissions of all manuscripts accompanied by a diskette containing the electronic files of the text, tables, and figures. Editors, authors, and reviewers will receive automatic e-mails when significant events occur.

We strongly encourage all authors and reviewers to use Editorial Manager. Although we will continue to accommodate the submission of paper manuscripts for some months, our goal is to be completely electronic within 9 to 12 months.

All individuals currently in our database for whom we have e-mail addresses will receive via e-mail a system-assigned username and password that can be used to log in to the system without prior registration. All those not receiving the e-mail must register the first time they use the system.

As with any broad systemic change, the conversion to the new system will take some time to complete. We ask your patience as we replace our in-office database with the new system. We also encourage you to take advantage of the speed and efficiency that the new system will provide for us all: editor, author, reviewer, and publisher. 